\title{
Parâmetros qualitativos do sêmen de jundiá (Rhamdia quelen) no inverno e na primavera
}

\section{Qualitative parameters of silver catfish (Rhamdia quelen) semen in spring and winter}

\author{
Frederico Aécio Carvalho Soares, ${ }^{*}$ Danilo Pedro Streit Jr., ${ }^{*}$ André Ricardo Ebert, ${ }^{*}$ Ivanir José Coldebella, ${ }^{* *}$ \\ Eneder Rosana Oberst ${ }^{\star * *}$
}

\begin{abstract}
Resumo
O presente estudo foi realizado com o objetivo de avaliar parâmetros qualitativos do sêmen de jundiá (Rhmadia quelen) em duas estações do ano, inverno e primavera. As amostras de sêmen foram coletadas de dezoito animais por método de extrusão nos meses de julho e novembro, sendo submetidas à análise de motilidade, vigor, concentração e morfologia espermáticos. $\mathrm{Na}$ análise de morfologia espermática, as células foram classificadas em normais, com defeito primário ou defeito secundário, além de a cabeça do espermatozoide ser classificada como alongada ou arredondada. Em julho, apenas 13 animais liberaram sêmen e, em novembro, todos os animais responderam positivamente à extrusão. Não houve diferença $(P>0,10)$ entre as duas coletas para as variáveis: concentração, espermatozoides normais, defeitos secundários e formato de cabeça. Para as variáveis defeitos primários, motilidade e vigor espermáticos, os resultados foram melhores na primavera $(\mathrm{P}<0,10)$. Os resultados mostram uma tendência à melhor qualidade do sêmen na primavera, porém foi possível se obter sêmen com qualidade também no inverno.
\end{abstract}

Palavras-chave: piscicultura, variações sazonais, sêmen, espermatozoides.

\begin{abstract}
The aim of the present study was evaluate qualitative parameters of silver catfish (Rhmadia quelen) semen in two seasons, winter and spring. Semen samples were collected from eighteen animals by extrusion method in July and November and were submitted to motility, vigor, concentration and morphology analysis. In the morphology analysis cells were classified in normal, with primary or secondary abnormalities and spermatozoa heads in round or elongated. In July, just thirteen animals released semen and in november all animals responded positively to extrusion releasing semen. No significant difference $(P>0,10)$ was found between the seasons for spermatic concentration, normal spermatozoa, secondary abnormalities and head morphology. For primary abnormalities, spermatic motility and vigor the results were better in spring $(P<0,10)$. The results show a tendency for better semen quality in spring, however was obtained semen with good quality in winter too.
\end{abstract}

Keywords: pisciculture, seasonal variations, semen, spermatozoa.

\section{Introdução}

O jundiá (Rhamdia quelen) é uma espécie nativa brasileira, de ampla distribuição geográfica, tendo sua ocorrência registrada desde a região central da Argentina até o sul do México (Silfvergrip, 1996). Sua carne tem uma boa aceitação no mercado consumidor, devido ao sabor e à ausência de espinhos intramusculares (Carneiro, 2002). A espécie possui uma boa adaptação a climas frios, tendo um papel importante na pesca extrativa e aquicultura da região sul do Brasil. De acordo com dados da Diretoria de Fauna e Recursos Pesqueiros do IBAMA, na atividade de pesca extrativa artesanal dos estados do Rio Grande do Sul e Santa Catarina, em 2005 foram pescados 395 e 11,5 toneladas de jundiá, respectivamente. Quanto à atividade de piscicultura, foram cultivadas 358 toneladas de jundiá no Rio Grande do Sul e 219,5 toneladas de jundiá em Santa Catarina no mesmo ano.

R. quelen vivem no fundo dos rios, preferindo ambientes de águas mais calmas com fundo de areia e lama, junto às margens e vegetação. Possuem hábito onívoro, alimentandose preferencialmente de peixes, crustáceos, insetos, restos vegetais e detritos orgânicos (Guedes, 1980; Meurer e Zaniboni Filho, 1997). Além disso, a espécie apresenta resistência às oscilações de temperatura e baixos níveis de oxigênio dissolvido na água (Zaions e Baldisserotto, 2000; Carneiro, 2002; Mello e Radünz Neto, 2002).

\footnotetext{
* Grupo de Pesquisa Aquam, Faculdade de Agronomia, UFRGS, Porto Alegre, RS. A quem enviar a correspondência. E-mail: fredaecio@gmail.com.

** Universidade Regional Integrada do Alto Uruguai e das Missões, Frederico Westphalen, RS.

*** Departamento de Patologia e Clínica Veterinária, Faculdade de Veterinária, UFRGS, Porto Alegre, RS.
} 
A qualidade do sêmen é de fundamental importância no processo de reprodução natural e artificial, refletindo no sucesso da fertilização. A eficiência deste processo está diretamente ligada à qualidade dos gametas, tanto masculinos quanto femininos. Assim como em algumas espécies de mamíferos, em peixes existem fatores ambientais que influenciam a reprodução. De acordo com Kuo et al. (1974), temperatura e fotoperíodo são os mais importantes fatores ambientais que interferem na reprodução dos peixes. Segundo Vazzoler (1996), temperatura da água, luz, precipitações pluviométricas, $\mathrm{pH}$ e disponibilidade de alimento são fatores ambientais que afetam a maturação gonadal dos peixes. Essa influência varia bastante de acordo com a espécie de peixe estudada.

O estudo teve como objetivo avaliar parâmetros qualitativos do sêmen de $R$. quelen em duas estações do ano, o inverno e a primavera.

\section{Material e métodos}

O experimento foi realizado em conjunto pela Universidade Regional Integrada do Alto Uruguai e das Missões (URI) e pelo grupo de pesquisa Aquam, da Universidade Federal do Rio Grande do Sul.

Os animais, 18 machos Rhamdia quelen com 14 meses de idade (todos filhos do mesmo casal de reprodutores), foram mantidos, por 18 semanas, em tanques-rede, submetidos às mesmas condições.

A obtenção de sêmen foi realizada em dois momentos distintos, inverno (julho) e primavera (novembro), sendo a avaliação dos parâmetros, motilidade e vigor espermáticos feita in loco. Porém, concentração e morfologia espermáticos foram analisados posteriormente, em laboratório.

Para a coleta de sêmen (sem indução hormonal), os animais foram contidos com uma toalha úmida, sendo a região da papila urogenital limpa e seca com papel-toalha e, em seguida, aplicada uma massagem anteroposterior na região abdominal.

Após a obtenção de sêmen, para a análise da motilidade e do vigor espermático, $0,02 \mu \mathrm{L}$ do material foi colocado em uma lâmina e homogeneizado com $0,16 \mu \mathrm{L}$ de água destilada. Com uma pipeta, 0,02 $\mu \mathrm{L}$ desta diluição foi colocado em outra lâmina e visualizado em um microscópio óptico, com objetiva de 40x. Por método subjetivo, a motilidade total foi classificada de 0 a $100 \%$ e o vigor espermático em pontos de 0 a 5 , de acordo com a velocidade e tipo de movimento das células.

Para as avaliações de concentração e morfologia espermática, as amostras foram fixadas em solução formol salina tamponada, com pipetas de precisão, nas diluições 1:1000 (primeira coleta) e 1:1500 (segunda coleta). Para a análise de concentração, usou-se a contagem em câmara de Neubauer, em microscópio óptico, com a objetiva de 40x. Por outro lado, a morfologia espermática de cada uma das amostras foi analisada por microscopia de contraste de fase, com objetiva de 100x. De cada amostra, foram tozoides. contadas 100 células, sendo classificadas em normais, com defeito primário ou com defeito secundário, de acordo com Blom (1950). Nesta mesma análise, classificou-se o formato de cabeça do espermatozoide em alongada e arredondada, pois estes diferentes formatos de cabeça são encontrados com frequência nas amostras de sêmen de peixes (Tuset et al., 2008).

Cada animal foi considerado uma unidade animal, onde 0 delineamento experimental seguiu o modelo, $\mathrm{Xij}=\mu+\mathrm{Pi}+$ Yij,

onde:

$$
\begin{aligned}
& \text { Xij = observação do animal (j) na estação do ano (i); } \\
& \mu=\text { erro associado ao modelo de predição; } \\
& \mathrm{Pi}=\text { período do ano (i); } \\
& \text { Yij = animal (j) na estação do ano (i). }
\end{aligned}
$$

Os dados foram submetidos à análise de variância utilizando o procedimento "npar1way" do pacote estatístico SAS (SAS Institute, Cary, USA).

\section{Resultados e discussão}

Em julho, dos 18 animais utilizados no experimento, 13 liberaram sêmen. Por outro lado, em novembro, todos os animais responderam positivamente após a extrusão (Tabela 1). Não foram encontradas diferenças $(P>0,10)$ entre as duas coletas para as variáveis: concentração espermática, espermatozoides normais, defeitos secundários, cabeça alongada e arredondada. Para as variáveis defeitos primários, motilidade e vigor espermáticos, os resultados foram melhores na primavera $(P<0,10)$. Inúmeros autores, estudando diferentes espécies de peixes, relacionam a atividade reprodutiva às variações sazonais de clima, temperatura e precipitação pluviométrica. Andrade e Braga (2005) avaliaram espécies de trecho lótico do rio Grande e demonstraram que as maiores frequências de maturação e esgotamento das gônadas foram observadas nos meses de temperatura do ar e pluviosidade elevados. Querol et al. (2004), estudando Loricariichthys platymetopon, relataram que o período de

Tabela 1: Médias ( \pm desvio-padrão) das características do sêmen de $R$. quelen criados em tanques-rede, no município de Frederico Westphalen, RS, coletados em julho e novembro de 2008

\begin{tabular}{lcc}
\hline \multicolumn{1}{c}{ Parâmetros seminais } & \multicolumn{2}{c}{ Coleta } \\
\cline { 2 - 3 } & Julho $(\mathrm{n}=13)$ & $\begin{array}{c}\text { Novembro } \\
(\mathrm{n}=18)\end{array}$ \\
\hline Motilidade (\%) & $68,46 \pm 19,08$ & $80,55 \pm 11,09^{*}$ \\
Vigor (1 a 5 pontos) & $1,84 \pm 0,37$ & $2,05 \pm 0,23^{*}$ \\
Concentração espermática $\left(\times 10^{9} / \mathrm{mm}^{3}\right)$ & $53,48 \pm 25,23$ & $48,16 \pm 20,26$ \\
Sptz normais (\%) & $93,07 \pm 3,59$ & $94,66 \pm 2,84$ \\
Defeitos primários (\%) & $2,53 \pm 1,98$ & $1,38 \pm 1,19^{*}$ \\
Defeitos secundários (\%) & $4,38 \pm 3,35$ & $3,94 \pm 2,57$ \\
Cabeça Arredondada (\%) & $40,15 \pm 14,32$ & $38,38 \pm 14,98$ \\
Cabeça Alongada (\%) & $59,30 \pm 14,32$ & $61,83 \pm 15,34$ \\
\hline
\end{tabular}

${ }^{*} \mathrm{P}<0,10$ quando comparadas as duas coletas; $n$, número de animais; sptz, esperma- 
maior insolação diária, aumento de temperatura e diminuição de índice pluviométrico apresentou influência no ciclo reprodutivo, acelerando a maturação gonadal e proporcionando a desova. Barbieri et al. (2000), em experimento com Salminus maxillosus e Prochilodus lineatus, verificaram correlação positiva entre incremento da relação gonadossomática e o aumento das temperaturas da água e do ar, precipitação atmosférica e fotoperíodo.

A motilidade espermática do sêmen dos $R$. quelen no presente estudo foi significativamente superior na primavera (média de $80,55 \%$ ), característica semelhante ao de outros trabalhos realizados com a mesma espécie. Quando Ferreira et al. (2001) realizaram coletas de sêmen no mês de novembro, encontraram índices de motilidade entre 60 e $85 \%$, com média de $72,5 \%$. Melhor qualidade do sêmen de jundiá também foi observada por Borges et al. (2005) na primavera, em comparação com as demais estações do ano, para parâmetros como volume, concentração espermática e tempo de duração da motilidade após a diluição. Entretanto, tal trabalho não verificou diferenças no percentual de motilidade espermática entre as amostras de sêmen coletadas na primavera e no inverno, sendo classificadas como classe máxima, em uma escala de 1 a 5 , em ambas as estações. Deve-se considerar que, no presente estudo, os animais foram mantidos em tanques-rede, expostos à variação ambiental, enquanto Borges et al. (2005) mantiveram os animais em condições controladas (tanques com água circulante desclorada, fotoperíodo natural e temperatura constante de $24 \pm 2{ }^{\circ} \mathrm{C}$ ), por pelo menos três dias antes da coleta e exame de sêmen.

Quanto ao vigor espermático, na primavera o resultado foi superior, com média de 2,05 contra 1,84 pontos no inverno. A explicação fisiológica para a melhor qualidade seminal do $R$. quelen na primavera, representada pela motilidade e vigor espermáticos, pode estar relacionada com os maiores picos de testosterona plasmática nesta espécie, que ocorrem nestes meses (Barcellos et al., 2002). O plasma seminal apresenta altos valores de $\mathrm{Na}$ e K (Borges et al., 2005), que devem ser responsáveis pela supressão da motilidade espermática, devido provavelmente ao seu efeito osmótico, conforme já referido em outras espécies de peixes (Billard, 1975; Benau e Terner, 1980; Morisawa et al., 1983; Morisawa, 1985). Após a diluição com água, o sêmen é imediatamente ativado e apresenta alta percentagem de espermatozoides com movimentação vigorosa e progressiva, mas com curta duração, de cerca de 20 segundos. A alteração osmótica pós-diluição ativa a motilidade espermática, mas as modificações que ocorrem no flagelo da célula espermática provavelmente determinam o curto tempo de duração da motilidade, conforme o referido também por Perchec et al. (1996), em Cyprinus carpio. No presente experimento, embora não tenha sido quantificado e analisado estatisticamente, o tempo de duração da motilidade espermática também foi reduzido, conforme o referido para amostras de sêmen de peixes, diluídas em água.

Quanto à concentração espermática, foram encontrados valores próximos a $50 \times 10^{9} \mathrm{sptz} / \mathrm{mm}^{3}$, variando de 24,8 a $116,65 \times 10^{9} \mathrm{sptz} / \mathrm{mm}^{3}$ no inverno e 1115 a $92,78 \times 10^{9} \mathrm{sptz} /$ $\mathrm{mm}^{3}$ na primavera. Tais valores são compatíveis com outros estudos realizados com $R$. quelen, como o de Ferreira et al. (2001), que observaram concentrações variando entre 24,65 e $138,95 \times 10^{9} \mathrm{sptz} / \mathrm{mm}^{3}$, com média $69,92 \times 10^{9} \mathrm{sptz} / \mathrm{mm}^{3}$; Fogli da Silveira et al. (1985), média de 55,79 x $10^{9} \mathrm{sptz} / \mathrm{mm}^{3}$; e Kavamoto e Fogli da Silveira (1986), valores variando entre 59,22 e $67,84 \times 10^{9} \mathrm{sptz} / \mathrm{mm}^{3}$. Por outro lado, a concentração espermática média registrada por Bombardelli et al. (2006) foi de $19,7 \times 10^{9} \mathrm{sptz} / \mathrm{mm}^{3}$, no entanto, os autores justificaram a baixa concentração devido à indução hormonal, que aumenta a produção de fluido seminal, reduzindo a concentração espermática. No presente estudo, não foi verificada diferença significativa de concentração espermática entre as estações, diferentemente do relatado por Borges et al. (2005), que encontraram entre as amostras de inverno e primavera concentrações de $50 \pm 1.2$ e $66 \pm 3.6 \times 10^{9} \mathrm{sptz} / \mathrm{mm}^{3}$, respectivamente. A concentração espermática apresenta grande amplitude de variação, de acordo com a espécie analisada e o período da temporada de desova. Tal parâmetro foi crescente durante a época de desova para diversas espécies, como Hippoglossus hippoglossus ( $\mathrm{M}$ ethven and Crim, 1991), Gadus morhua (Rakitin et al., 1999) e Salmo salar m. sebago Girard (Piironen, 1985). Já para Tinca tinca (Zuromska, 1981), Salmo gairdneri (Munikittrick e Moccia, 1987), Sparus aurata e Dicentrarchus labrax (Kara e Labed, 1994), a concentração mostrou-se decrescente na época da desova.

Com relação à morfologia espermática, o percentual de espermatozoides normais foi elevado e não apresentou variação significativa entre as estações, sendo 93,07\% $\pm 3,59$ no inverno e $94,66 \% \pm 2,84$ na primavera. Os defeitos encontrados foram: cauda simplesmente dobrada $(49,7 \%)$, cauda quebrada $(22,6 \%)$, cabeça solta $(18,8 \%)$, cauda enrolada na porção final $(3,3 \%)$, cabeça deformada $(2,2 \%)$, inserção abaxial $(1,7 \%)$, peça dupla $(1,1 \%)$ e cauda fortemente enrolada $(0,6 \%)$. A análise dos defeitos espermáticos das amostras deste experimento foi baseada na classificação de Blom (1950), que considera como anormalidades primárias os defeitos espermáticos ocorridos durante a espermatogênese e, como anormalidades secundárias, aqueles defeitos que ocorrem no espermatozoide já formado. Esta classificação foi utilizada com o objetivo de verificar a influência da época do ano nos defeitos espermáticos diretamente originários do testículo, que ocorrem na formação da célula espermática. Alguns autores (Girão e Mies Filho, 1985; Mies Filho et al., 1990; Sousa e Costa, 1992) utilizaram esta classificação para evidenciar efeitos ambientais (luz, temperatura) na produção espermática de ovinos e caprinos. As patologias espermáticas também podem ser classificadas em defeitos maiores e menores, de acordo com Blom (1973), método que é indicado pelo Colégio Brasileiro de Reprodução Animal (CBRA, 1998) e visa avaliar principalmente a fertilidade da amostra. Mesmo utilizando-se esta classificação, verifica-se que nas amostras avaliadas, o índice de defeitos totais sempre foi inferior a 5\%. Ocorreu o predomínio de defeitos menores, especialmente o defeito denominado cauda dobrada.

Os defeitos espermáticos podem alterar os índices de fertilidade na reprodução natural e, em espécies de reprodução estacional, como ovinos, caprinos, equinos e aves, apresentam grande variação sazonal. Em ovinos, a análise dos defeitos espermáticos é considerada um dos mais importantes critérios de avaliação da qualidade do sêmen (Colas, 1979). Apresenta também grande importância 
em amostras submetidas à refrigeração/congelação, pois os procedimentos de conservação do sêmen podem causar inúmeras lesões aos espermatozoides e, assim, reduzir a fertilidade das amostras. Índices de patologias espermáticas totais de $30 \%$, em equinos e bovinos, e de $20 \%$, em suínos e ovinos, são considerados aceitáveis e compatíveis com índices normais de fertilidade nas espécies citadas (CBRA, 1998). Em peixes, diferente do que ocorre nestas outras espécies, ainda não existe uma classificação quanto a valores de patologias espermáticas consideradas normais, portanto, o aumento de pesquisas sobre este parâmetro seria de suma importância para tal.

Existem poucos dados sobre a avaliação morfológica dos espermatozoides de peixes e, na maioria, as análises utilizam a microscopia eletrônica, como Thunken et al. (2007), Psenicka et al. (2008) e Alavi et al. (2009). Porém, a técnica não pode ser utilizada como rotina nas análises de sêmen, em função do custo e praticidade. Alguns outros autores utilizaram técnicas de coloração e visualização em microscopia óptica, como, por exemplo, Streit Jr. et al. (2004). Estes autores testaram diferentes soluções fixadoras e corantes para análise morfológica de amostras de sêmen de Piaractus mesopotamicus e concluíram que a melhor combinação foi do corante Rosa Bengala com a solução fixadora formol salina tamponado. No presente estudo, as avaliações da morfologia foram realizadas em microscopia de contraste de fase, o que reduz as alterações decorrentes tanto da confecção do esfregaço quanto do uso de corantes, além de ser um método barato e de fácil realização.

É importante ressaltar que não existem ainda padrões mínimos e ideais, tanto para os parâmetros de qualidade do sêmen quanto para os de doses inseminantes, além de estes valores variarem consideravelmente entre as diferentes espécies de peixes. Um bom indicativo a respeito

\section{Conclusão}

Os resultados mostrados neste trabalho evidenciam uma tendência à melhor qualidade do sêmen dos $R$. quelen na

\section{Referências}

ALAVI, S.M.H.; PSENICKA, M.; POLICAR, T.; RODINA, M. HAMÁCKOVÁ J.; KOZÁK, P.; LINHART, O. Sperm quality in male Barbus barbus L. fed different diets during the spawning season. Fish Physiol Biochem, v. 35 p. $683-693,2009$.

ANDRADE, P.M.; BRAGA, F.M.S. Reproductive seasonality of fishes from a lotic stretch of the Grande river, High Paraná river basin, Brazil. Braz J Biol, v. 65, n. 3, p. 387-394, 2005.

BARBIERI, G.; SALLES, F.A.; CESTAROLLI, M.A. Influência de fatores abióticos na reprodução do dourado, Salminus maxillosus e do curimbatá, Prochilodus lineatus do Rio Mogi Guaçu (Cachoeira de Emas, Pirassununga/SP). Acta Limnol Bras, v. 12, p. 85-91, 2000.

BARCELLOS, L.J.G.; WASSERMAN, G.F.; SCOTT, A.P.; WOEHL, V.M.; QUEVEDO, R.M.; ITTZÉS, I.; KRIEGER, M.H.; LULHIER, F. Plasma steroid concentrations in relation to the reproductive cycle of cultured male Rhamdia quelen. Journal of Fish Biology, v. 61, p. 751-763, 2002.

BENAU, D.; TERNER, C. Initiation, prolongation and reactivation of the motility of salmonid spermatozoa. Gamete Res, v. 3, p. 247-257, 1980. de parâmetros seminais relacionados com a dose inseminante foi observado por Bombardelli et al. (2006), testando reprodução artificial em jundiás. A partir de um pool de sêmen, tendo concentração espermática de $19,7 \times 10^{9}$ sptz/mL e $66,9 \%$ de células normais na análise de morfologia, uma dose inseminante de 89.497 espermatozoides.ovócito-1 teve taxa de fertilização máxima teórica de 86,68 \%. A partir da comparação com tal trabalho, o sêmen dos animais do presente estudo apresentou valores de concentração e morfologia espermáticas superiores, tanto no inverno quanto na primavera. Assim, talvez com estas amostras fosse possível, com uma dose inseminante menor ou igual a que foi referida por Bombardelli et al. (2006), atingir-se taxas de fertilização iguais ou superiores.

O formato da cabeça do espermatozoide, avaliado subjetivamente e classificado como alongado ou arredondado, não apresentou variação significativa entre as coletas, embora em ambas o formato arredondado tenha prevalecido. Em experimento realizado com sêmen de Atlantic cod, utilizando método computadorizado de análise de sêmen, Tuset et al. (2008) também encontraram espermatozoides com estes dois formatos de cabeça, porém a cabeça alongada estava bem mais presente. Não se sabe por que ocorre essa variação no formato da cabeça dos espermatozoides em um mesmo animal. Uma hipótese a ser considerada estaria relacionada com a osmolalidade, de acordo com as alterações descritas por Perchec et al. (1996), em Cyprinus carpio. Outras hipóteses levantadas relacionam a influência da idade do animal, maturação celular, artefato de preparação do esfregaço nas lâminas ou, ainda, que seja um defeito na forma do espermatozóide. No entanto, é importante que mais pesquisas sejam feitas para esclarecer se o formato da cabeça do espermatozoide pode ou não influenciar a taxa de fertilização.

primavera. No entanto, os resultados também mostram que é possível se obter sêmen de peixes desta espécie com qualidade no inverno.

BILLARD, R. L'insémination artificielle de la truite Salmo gairdneri Richardson. IV. Effects des ions $\mathrm{K}+$ et $\mathrm{Na}+$ sur la conservation du pouvoir fécondant des gamètes. Bull Fr Piscic, v. 256, p. 88-98, 1975.

BLOM, E. A one minute live-dead sperm by means of eosin-nigrosin. Fertility and sterility, v. 1, n. 2, p. 176-177, 1950.

BLOM, E. The ultrastructure of some characteristics sperm defects and a proposal for a new classification of bull spermiogram. Nord Veterinary Medicine, v. 25, p. 383-391, 1973.

BOMBARDELLI, R.A.; MÖRSCHBÄCHER, R.C.; CAMPAGNOLO, R.; SANCHES, E.A.; SYPERRECK, M.A. Dose inseminante para fertilização artificial de ovócitos de jundiá cinza, Rhamdia quelen (Quoy \& Gaimard, 1824). R Bras Zootec, v. 35, n. 4, p. 1251-1257, 2006.

BORGES, A.; SIQUEIRA, D.R.; JURINITZ, D.F.;ZANINI, R.; DO AMARAL, F.; GRILLO, M.L.; OBERST, E.R.; WASSERMAN, G.F. Biochemical composition of seminal plasma and annual variations in semen characteristics of jundiá Rhamdia quelen (Quoy and Gaimard, Pimelodidae). Fish Physiol Bichem, v. 31, p. 45-53, 2005.

CARNEIRO, P.C.F.; BENDHACK, F.; MIKOS, J.D. Jundiá: um grande peixe para a Região Sul. Panorama da Aquicultura, v. 12, p. 41-46, 2002. 
CBRA. Colégio Brasileiro de Reprodução Animal. Manual para exame andrológico e avaliação de sêmen animal. 2. ed. Belo Horizonte: CBRA, 1998. 54 p.

COLAS, G. Fertility in the ewe after artificial insemination with fresh and frozen semen at the induced oestrus, and influence of the photoperiod on the semen quality of the ram. Livest Prod Sci, v. 6, p. 153-166, 1979.

FERREIRA, A.A.; NUÑER, A.P.O.; LUZ, R. K., TATAJE, D.A.R.; ESQUIVEL, J.R.; RESTREPO, J.B. Avaliação qualitativa e quantitativa do sêmen de jundiá, Rhamdia quelen. $B$ Inst Pesca, v. 27, n. 1, p. 5760, 2001.

FOGLI DA SILVEIRA, W.; KAVAMOTO, E.T.; NARAHARA, N.Y. Avaliação da qualidade e criopreservação em dorma de "pellets" do sêmen do bagre, Rhamdia hilarii (Valenciennes, 1840). B Inst Pesca, v. 12, n. 4, p. 7-11, 1985

GIRÃO, R.N.; MIES FILHO, A. Características do sêmen de carneiros Corriedale mantidos em fotoperíodo e temperatura controlados e naturais. Pesq Agropec Bras, v. 20, n. 12, p. 1395-1407, 1985.

GUEDES, D.S. Contribuição ao estudo da sistemática e alimentação de jundiás (Rhamdia spp) na região central do Rio Grande do Sul (Pisces, Pimelodidae). 1980. 99p. Tese (Mestrado)-Curso de Pósgraduação em Zootecnia, Universidade Federal de Santa Maria. 1980.

IBAMA. Estatística da pesca 2005. Brasil. Grandes regiões e unidades da federação. Brasília, 2006. 115 p.

KARA, M.H.; LABED, S. Evolution of the sperm characteristics of Sparus aurata and Dicentrarchus labrax during the period of reproduction. Cah Biol Mar, v. 35, n. 3, p. 281-288, 1994.

KAVAMOTO, E.T.; FOGLI DA SILVEIRA, W. Características físicas, químicas e microscópicas do sêmen do bagre Rhamdia hilarii (Valenciennes, 1840) em condições de campo. B Inst Pesca, v. 13, n. 1, p. 95-100, 1986.

KUO, C.M.; NASH, C.E.; SHEHADEH, Z.H. The effects of temperature and photoperiod on ovarian development in captive grey-mullet (Mugil cephalus L.). Aquaculture, v. 3, p. 25-43, 1974.

MELLO, J.F.B.; RADÜNZ NETO, S.J. Desenvolvimento e composição corporal de alevinos de jundiá (Rhamdia quelen) alimentados com dietas contendo diferentes fontes de lipídios. Ciência Rural, v. 32, n. 2, p. 321-327, 2002.

METHVEN, D.A.; CRIM, L.W. Seasonal changes in spermatocrit, plasma sex steroids, and motility of sperm from Atlantic halibut, Hippoglossus hippoglossus. FOURTH INT. SYMP. REPROD. FISH, Sheffield, 1991, p.170.

MEURER, S.; ZANIBONI FILHO, E. Hábito alimentar do jundiá Rhamdia quelen (Pisces, Siluriformes, Pimelodidae), na região do alto rio Uruguai. XII ENCONTRO BRASILEIRO DE ICTIOLOGIA, São Paulo, SP. Anais..., 1997. p. 29.

MIES FILHO, A.; GIRÃO, R.N.; OBERST, E.R.; WALD, V.B. Influence bènefique d'un éclairment quotidien de $8 \mathrm{~h}$ sur la spermatogènése du bélier au Brésil. Bull Acad Vet de France, v. 73, p. 409-413, 1990.

MORISAWA, M. Initiation mechanism of sperm motility at spawning in teleosts. Zool Sci, v. 2, p. 605-615, 1985.
MORISAWA, M.; SUZUKI, K.; MORISAWA, S. Effects of potassium and osmolality on spermatozoan motility of salmonid fishes. J Exp Biol, v. 107, p. 105-113, 1983.

PERCHEC, G.; COSSON, M.P.; COSSON, J.; JEULIN, C.; BILLARD, R. Morphological and kinetic changes of carp (Cyprinus carpio) spermatozoa after initiation of motility in distilled water. Cell Motil Cytoskel, v. 36, p.113-120, 1196.

PIIRONEN, J. Variation in the properties of milt from the Finnish landlocked salmon (Salmo salar m. sebago Girard) during a spawning season. Aqauaculture, v. 48, p. 337-350, 1985.

PSENICKA, M.; ALAVI, S.M.H.; RODINA, M.; CICOVA, Z.; GELA, D.; COSSON, J.; NEBESAROVA, J.; LINHART, O. Morphology, chemical contents and phisiology of chondostrean fish sperm: a comparative study between Siberian sturgeon (Acipenser baerii) sterlet (Acipenser ruthenus). J Appl Ichthyol, v. 24, p. 371-377, 2008.

QUEROL, M.V.M.; QUEROL, E.; PESSANO, E.F. Influência de fatores abióticos sobre a dinâmica da reprodução do cascudo viola Loricariichtys platymetopon (Isbrucker \& Nijssen, 1979) (Ostheichthyes, Loricariidae), no reservatório da estância Nova Esperança, Uruguaiana, Bacia do Rio Uruguai, RS, Brasil. Biodiversidade Pampeana, v. 2, p. 24-29, 2004.

RAKITIN, A.; FERGUSON, M.M.; TRIPPEL, E.A. Spermatocrit and spermatozoa density in Atlantic cod (Gadus morhua): correlation and variation during the spawning season. Aquaculture, v. 70, p. 349-358, 1999.

SILFVERGRIP A.M.C. A sistematic revision of the neotropical catfish genus Rhamdia (Teleostei, Pimelodidae). 1996. 156 p. Tese (PhD). Stockholm, Sweden, 1996.

SOUSA, J.A.T.; COSTA, F.A.L. Características do sêmen e correlação com outros parâmetros reprodutivos em ovinos deslanados. SIMPÓSIO EM CIÊNCIAS AGRÁRIAS-PESQUISA COM CAPRINOSEOVINOSNO CAA, 1992, Teresina. Anais..., 1992, p. 80-86.

STREIT JR, D.P.; MORAES, G.V.; RIBEIRO, R.P.; POVH, J.A.; SOUZA, E.D.; OLIVEIRA, C.A.L. Avaliação de diferentes técnicas para coloração de sêmen de peixes. Arq Ciênc Vet Zool UNIPAR, v. 7, n. 2, p.157-162, 2004.

THÜNKEN, T.; BAKKER, T.C.M.; KULLMANN, H. Extraordinarily long sperm in the socially monogamous cichlid fish Pelvicachromis taeniatus. Naturwissenschaften, v. 94, p. 489-491, 2007.

TUSET, V.M.; TRIPPEL, E.A.; DE MONSERRAT, J. Sperm morphology and its influence on swimming speed in Atlantic cod. J Appl Ichthyol, v. 24, p. 398-405, 2008.

VAZZOLER, A.E.A.M. Biologia da reprodução de peixes teleósteos: teoria e prática. Nupelia, Maringá-PR, 169 p.,1996.

ZAIONS, M.I.; BALDISSEROTTO, B. Na+ and $\mathrm{K}+$ body levels and survival of fingerlings of Rhamdia quelen (Siluriformes, Pimelodidae) exposed to acute changes of water pH. Ciência Rural, v. 30, n. 6, p. 1041-1045, 2000.

ZUROMSKA, $\mathrm{H}$. Effect of different thermal regime on reproductive cycles of tench, Tinca tinca (L.). Part IV. Estimation of milt quality. Pol Arch Hydrobiol, v. 28, p. 229-242, 1981. 